\title{
EXPERIMENTAL STUDY OF UNLIPPED CHANNEL BEAMS SUBJECT TO WEB CRIPPLING UNDER ONE FLANGE LOAD CASES
}

\author{
Shanmuganathan Gunalan and Mahen Mahendran *
}

${ }^{1}$ Queensland University of Technology, Brisbane, Australia

*(Corresponding author: E-mail: m.mahendran@qut.edu.au)

\section{A B S T R A C T}

Cold-formed steel members are becoming increasingly popular in the building industry due to their superior strength to weight ratio and ease of fabrication as opposed to hot-rolled steel members. However, they are susceptible to various buckling modes at stresses below the yield stress of the member because of their relatively high width-to-thickness ratio. Web crippling is one of the failure modes that occurs in steel channel sections under transverse concentrated loads or reactions. Recently a test method has been proposed by AISI to obtain the web crippling capacities under both one-flange and two-flange load cases. Using this test method 21 tests were conducted in this research to investigate the web crippling behaviour and strengths of an unlipped channel section with stocky webs known as DuraGal Channels under end-one-flange (EOF) and interior one-flange (IOF) load cases. DuraGal channels with different web slenderness and bearing lengths were tested with their flanges unfastened to supports. In this research the suitability of the currently available design rules for unlipped channels subject to web crippling under one flange load cases was investigated, and suitable modifications were proposed where necessary. This paper presents the details of this ex perimental study and the results.

\section{A R T I C L E H I S T O R Y}

$\begin{array}{ll}\text { Received: } & \text { 25 November } 2017 \\ \text { Revised: } & \text { 14 June 2018 } \\ \text { Accepted: } & \text { 26 August } 2018\end{array}$

\section{K E YWO R D S}

Cold-formed steel structures;

Unlipped channels;

Web crippling;

EOF and IOF load cases

Stocky web

\section{Introduction}

Cold-formed steel members have many advantages over hot-rolled steel members. Among them DuraGal channel sections are commonly used as bearers of floor systems in residential, industrial and commercial buildings [1]. They are thicker channel sections with varying geometry to suit various requirements including higher moment capacities and longer spans. Figure 1(a) shows the DuraGal channel section profile while Figure 1(b) shows its applications in buildings as joists and bearers. Table 1 shows the nominal dimensions of DuraGal channel sections available in the market.

Web crippling is a form of localized failure mode that can occur when the members are subjected to transverse concentrated loadings and/or reactions. (see Figure 2). Cold-formed steel joists and bearers that are unstiffened against this type of loading are vulnerable to these failures. In a typical floor system, web crippling failures can occur at bearer to column and joist to bearer connections depending on various structural details given in Table 2. Failure modes of bearers can be different according to the loading locations such as interior columns, end columns and joists supported by bearers. One-flange loading or reaction occurs when the clear distance between the bearing edges of adjacent opposite concentrated actions or reactions is greater than $1.5 d_{l}$, where $d_{l}$ is the depth of the flat portion of the web. Two-flange loading or reaction occurs when the clear distance between the bearing edges of adjacent opposite concentrated actions or reactions is less than or equal to $1.5 d_{l}$. End loading or reaction occurs when the distance from the edge of the bearing to the end of the member is less than or equal to $1.5 d_{l}$ while interior loading or reaction occurs when the distance from the edge of the bearing to the end of the member is greater than $1.5 d_{l}$. To simulate these practical loading conditions, there are four loading cases for web crippling as recommended in the cold-formed steel specifications including American and Australian standards [2,3]. These loading cases are used to investigate the web crippling capacities of cold-formed steel beams. They are End-One-Flange (EOF), End-Two-Flange (ETF), Interior-One-Flange (IOF) and Interior-Two-Flange (ITF) loading as shown in Figure 3.

Current cold-formed steel design rules to predict the web crippling capacities are empirical as they were developed based on extensive testing of many cold-formed steel sections such as C-, Z- and hat sections and built-up sections undertaken since 1940s [4-28]. Since 2005, a unified bearing capacity equation has been developed that defines specific coefficients for the key parameters influencing the bearing capacities of C-, Z-, Hat and built-up sections [13]. They are clear web height to thickness ratio $\left(d_{l} / t_{w}\right)$, inside bent radius to thickness ratio $\left(r_{i} / t_{w}\right)$, bearing length to thickness ratio $\left(l_{b} / t_{w}\right)$, in addition to web thickness $\left(t_{w}\right)$ and yield stress $\left(f_{y}\right)[2,3]$. However, it should be noted that these capacity equations are not applicable to some of the DuraGal channels due to their large inside bent radius to thickness ratios $\left(r_{i} / t_{w}\right)$.

The details of suitable test procedures that should be adopted in web crippling studies are presented in the AISI standard test method published in
2008. These test procedures are different to those used by Young and Hancock $[19,20]$ who investigated the web crippling behaviour of DuraGal channels using experimental studies. The AISI standard test method [29] recommends that the test specimen shall be both laterally and torsionally stable. Thus, for a channel section where the geometry does not permit the application of the load through the shear centre, the test specimen shall consist of two opposed sections. The cold-formed steel shapes shall be interconnected using rigid connecting elements such as angles to form the box shape. When using rigid connecting elements, they shall be located at approximately the $1 / 4$ and $3 / 4$ points along the longitudinal axis of the box shape. However, the test set-ups used in the past research $[19,20]$, are different to those recommended by the AISI standard test method [29] for EOF and IOF load cases. Hence there is a need to investigate the effects of test set-up given in the AISI standard test method on web crippling capacities.

This research is aimed at investigating the web crippling behaviour and strength of unlipped channels with stocky webs under EOF and IOF load cases and determining the accuracy of currently used design rules. Test specimen length and test setup were selected based on the AISI standard test method [29] Experimental web crippling capacities were compared with the predicted web crippling capacities using the current design rules and suitable modifications were proposed where necessary.

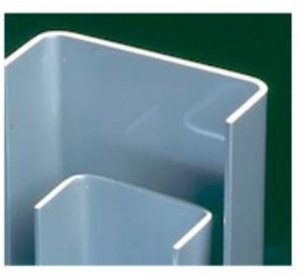

(a) Duragal channel section

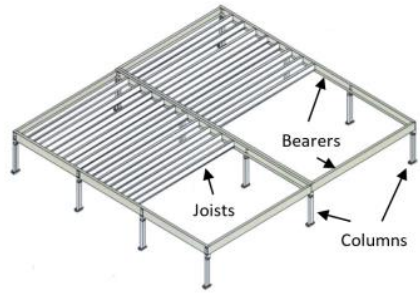

(b) Floor system
Fig. 1 Cold-formed steel floor systems
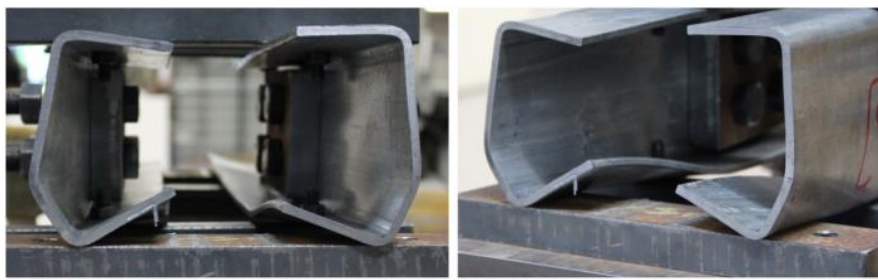

Fig. 2 Web crippling failure at a reaction point 
Table 1

Duragal channel sections

\begin{tabular}{ccccc}
\hline Section & Depth $(\mathrm{mm})$ & Flange $(\mathrm{mm})$ & Thickness $(\mathrm{mm})$ & Radius $(\mathrm{mm})$ \\
\hline $300 \times 90 \times 8$ & 300 & 90 & 8.0 & 8 \\
$300 \times 90 \times 6$ & 300 & 90 & 6.0 & 8 \\
$250 \times 90 \times 6$ & 250 & 90 & 6.0 & 8 \\
$230 \times 75 \times 6$ & 230 & 75 & 6.0 & 8 \\
$200 \times 75 \times 6$ & 200 & 75 & 6.0 & 8 \\
$200 \times 75 \times 5$ & 200 & 75 & 4.7 & 4 \\
$180 \times 75 \times 5$ & 180 & 75 & 4.7 & 4 \\
$150 \times 75 \times 5$ & 150 & 75 & 4.7 & 4 \\
$125 \times 65 \times 4$ & 125 & 65 & 3.8 & 4 \\
$100 \times 50 \times 4$ & 100 & 50 & 3.8 & 4 \\
$75 \times 40 \times 4$ & 75 & 40 & 3.8 & 4 \\
\hline
\end{tabular}

Table 2

Different conditions for single web channel sections

\begin{tabular}{cc}
\hline Conditions & Options \\
\hline Support condition & Fastened versus Unfastened \\
Flange condition & Stiffened (lipped) versus Unstiffened (unlipped) \\
Loading condition & EOF, IOF, ETF and ITF load cases \\
\hline
\end{tabular}

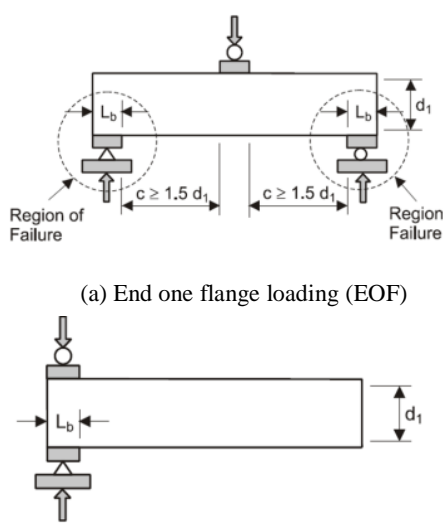

(c) End two flange loading (ETF)

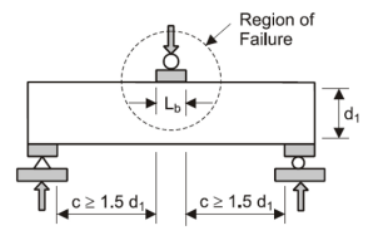

(b) Interior one flange loading (IOF)

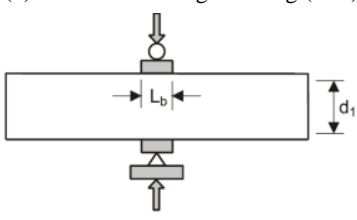

(d) Interior two flange loading (ITF)
Fig. 3 Loading conditions for web crippling tests $[2,3]$

\section{Previous studies on web crippling}

Theoretical elastic methods [30-32] can be used to analyse the web crippling behaviour of cold-formed steel members subjected to different load conditions. However, it should be noted that the web element of a cold-formed steel member is not identical to a four sided simply supported rectangular plate. The web of a cold-formed steel member cannot be considered as a rectangular plate with idealized boundary conditions (simply supported or clamped at its four sides). Also, the determination of critical elastic buckling load does not necessarily imply the failure of the web. Hence the additional load carrying capacity developed in the web beyond the elastic buckling load should be estimated. Due to these difficulties associated with the theoretical analysis, the development of web crippling design equations in most of the previous studies were based on experimental data.

Winter and Pian [4] investigated the web crippling capacities of coldformed steel I-sections under four different load cases while Baehre [7] investigated the web crippling capacities of hat sections subjected to IOF loading. Hetrakul and Yu [8] researched the web crippling behaviour of coldformed steel sections having single unreinforced webs. Wing [9] and Wing and Schuster [10] investigated the web crippling capacities of multi-web coldformed steel sections under all load cases, except for EOF loading case. In this study the test specimens were fastened to the reaction supports. Santaputra et al. [11] conducted web crippling tests of hat sections and I-beams fabricated from very high-strength steels under various loading conditions. Bhakta et al. [12] experimentally investigated the influence of flange restraint on the web crippling capacity of beam web elements.
Prabakaran [13] completed an extensive statistical analysis of the web crippling capacities of cold-formed steel sections by using the available experimental data found in the literature with an aim to develop one simplified design equation. He recommended a unified equation with different coefficients for the design of I-sections, single web sections and multi-web sections. Cain et al. [14] experimentally investigated the web crippling of Z-sections subjected to EOF loading and I-sections subjected to IOF loading. Gerges [15] and Gerges and Schuster [16] investigated the web crippling resistance of single web coldformed steel members with large inside bent radius to thickness $\left(r_{i} / t_{w}\right)$ ratios, subjected to EOF loading. Also they developed new parameter coefficients for Prabakaran's [13] web crippling equation based on tests performed on Csections fastened to the support. An experimental study of stiffened C-and Zsections subjected to web crippling was carried out by Beshara and Schuster [17]. ETF and ITF loading conditions were considered with particular emphasis on large $r_{i} / t_{w}$ ratios, and the specimens being fastened to the support.

An experimental investigation was carried out by Young and Hancock [20] to investigate the behaviour of cold-formed unlipped DuraGal channels subjected to web crippling under all four loading conditions (EOF, IOF, ETF and ITF). Figure 4 shows the test set-up used by Young and Hancock [20] for IOF load case. Based on the results of their research, the design web crippling strength predictions given by the old American and Australian standards [33,34] were found to be unconservative for the unlipped channel sections. In their paper, a simple plastic mechanism expression for web crippling strength of unlipped channels is also proposed. Macdonald et al. [21] conducted experimental and numerical studies to investigate the web crippling behaviour of lipped channel beams under ETF, ITF, EOF and IOF load cases. Figure 5 shows the experimental setup used in Macdonald et al.'s [21] tests. They found that the bearing length, corner radii and clear height of web had an effect on the web crippling strength of lipped channel beams (LCB), particularly for EOF and IOF load cases. Uzzaman et al. [23-26] and Yousefi el al. [27,28] conducted experimental and numerical studies to investigate the effect of offset web holes on the web crippling strength of cold-formed steel lipped channel beams. They also did web crippling tests of LCBs without web openings.

Recent web crippling studies also included an experimental investigation of a new hollow flange channel beam [35,36] and LCBs [37] under EOF and IOF load cases. Their study led to suitable web crippling design rules based on AS/NZS 4600 and AISI S100 design standards. As part of their studies on DuraGal channel beams, Gunalan and Mahendran [38] conducted an experimental investigation into the web crippling capacities of cold-formed steel unlipped channels with stocky webs under ETF and ITF load cases. The flanges of these channel sections were not fastened to the supports in this study. It was found that the specimen lengths proposed by the AISI testing method should be used for the web crippling tests under ETF and ITF load cases. A detailed comparison of ultimate web crippling capacity results with those predicted by the current design equations in AS/NZS 4600, AISI S100 and Young and Hancock [20] showed that these equations are unconservative for these stocky channel sections under ETF and ITF load cases. Hence new design equations were proposed within these guidelines to accurately predict the web crippling capacities of unlipped channel sections based on test results.

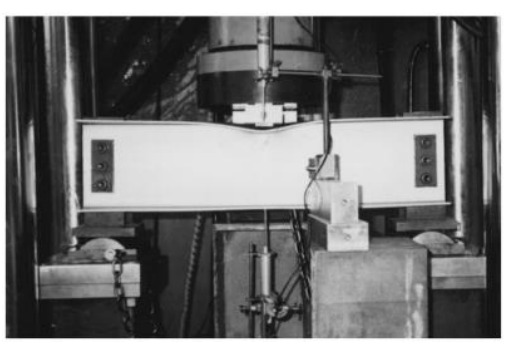

(a) End view

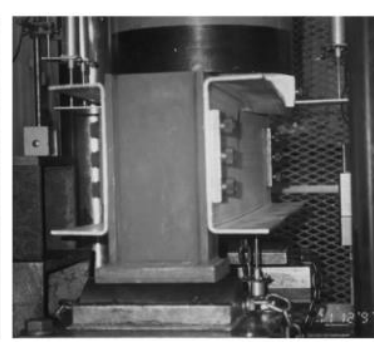

(b) Front view
Fig. 4 Young and Hancock's [20] web crippling test set-up for IOF load case

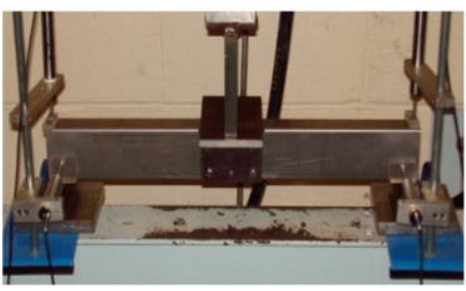

(a) EOF load case

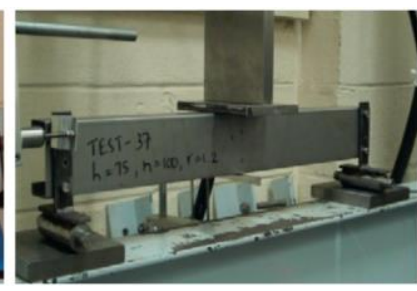

(b) IOF load case
Fig. 5 Macdonald et al.'s [21] web crippling test set-up 


\section{Current design rules}

\subsection{AS/NZS 4600 and AISI S100}

Many different design equations have been proposed and used to predict the web crippling capacity in the past. Web crippling research commenced in 1939 at Cornell University with the first design specification published in 1940 by the American Iron and Steel Institute. Subsequent research at various institutions throughout the world led to the present day design standards in both AS/NZS 4600 [3] and AISI S100 [2]. In the older version of American Specification [33], different design equations were used to predict the web crippling capacity of cold-formed steel beams. Each of these design equations is only applicable to a certain type of cross section geometry and a particular load case. However, the new unified web crippling capacity equation (Equation 1) adopted in AS/NZS 4600 [3] and AISI S100 [2] is applicable to different types of section geometry and load cases (ETF, ITF, EOF and IOF). These standards provide design guidelines for the bearing capacity $\left(R_{b}\right)$ of open coldformed steel sections, which is based on Prabakaran [13] who performed an extensive statistical analysis of more than 1200 experimental web crippling capacities of a range of cold-formed steel sections and proposed a suitable unified design equation based on four web crippling coefficients (Equation 1). This design rule takes into consideration the clear height of web to thickness ratio $\left(d_{l} / t_{w}\right)$, inside bent radius to thickness ratio $\left(r_{i} / t_{w}\right)$, bearing length to thickness ratio $\left(l_{b} / t_{w}\right)$, yield stress $\left(f_{y}\right)$ and web thickness $\left(t_{w}\right)$. Suitable values of the four coefficients in Equation 1 are given in Table 3 for unlipped channels under EOF and IOF load cases, where the flanges are not connected to the supports (unfastened). It should be noted that these coefficients are applicable for section where the inside bent radius to thickness ratio $\left(r_{i} / t_{w}\right)$ is less than or equal to one.

$R_{b}=C t_{w}^{2} f_{y} \sin \theta\left(1-C_{r} \sqrt{\frac{r_{i}}{t_{w}}}\right)\left(1+C_{l} \sqrt{\frac{l_{b}}{t_{w}}}\right)\left(1-C_{w} \sqrt{\frac{d_{1}}{t_{w}}}\right)$

where $C=$ coefficient; $t_{w}=$ thickness of web; $f_{y}=$ yield stress; $r_{i}=$ inside bent radius; $l_{b}=$ bearing length; $d_{l}=$ depth of the flat portion of the web measured along the plane of the web; $\theta=$ angle between the plane of the web and the plane of the bearing surface; $C_{r}, C_{l}$ and $C_{w}=$ coefficients of inside bent radius, bearing length and web slenderness, respectively.

\subsection{Young and Hancock [20]}

Young and Hancock [20] conducted an experimental study on cold-formed unlipped DuraGal channels with comparatively stocky webs subjected to web crippling. Figure 4 shows their test set-up used for IOF load case where support reaction were transferred through the section web which is different to the test method given in AISI standard test method [29]. The specimen lengths were taken as $3\left(l_{b}+d\right)$ for both EOF and IOF load cases where $l_{b}$ is the bearing length and $d$ is the overall depth of the section. Test results were compared with the design equations in the older version of AS/NZS 4600 [34] and AISI [33]. It was found that these design equations are accurate under EOF load case, but are unconservative under IOF load case for unlipped channels.
The web crippling capacities of DuraGal channels from their tests are compared with the predictions from the current design equations based on AS/NZS 4600 [3] and AISI S100 [2] (Tables 4 and 5). The design rules in AS/NZS 4600 are identical to those in AISI S100, and hence only AS/NZS 4600 values are reported in this paper. Overall twisting failure was observed for Section $75 \times 45 \times 4$ and hence it was ignored in these tables. The mean values of test to predicted web crippling capacities of unlipped channels by AS/NZ 4600 [3] are 0.83 and 0.86 for EOF and IOF load cases, respectively. The corresponding coefficients of variation $(\mathrm{COV})$ are 0.09 and 0.04 , respectively. Tables 4 and 5 results show that AS/NZS 4600 [3] and AISI S100 [2] design equations are up to $32 \%$ unconservative for some of the channel sections when higher bearing lengths are used. Hence there is a need to investigate the applicability of the current AS/NZS 4600 and AISI S100 design equations for increased bearing lengths. Also, it should be noted that these design equations restricts the $r_{i} / t_{w}$ ratio to one (Table 3 ) for IOF load case and hence are not applicable to many DuraGal sections in Table 5.

Young and Hancock [20] also developed design equations to predict the web crippling capacities of channels with stocky webs based on their test results. These equations were derived using a combination of theoretical and empirical analyses. It was assumed that the bearing load is applied eccentrically to the web due to the presence of the corner radii, which produces bending of the web out of its plane. This will lead to a plastic mechanism as shown in Figures 6 and 7 .

$P_{p m}=\frac{M_{p} N_{m}}{r}\left[C_{a}-C_{b}\left(\frac{h}{t}\right)\right]$

$M_{p}=\frac{f_{y} t_{w}^{2}}{4}$

$r=r_{i}+\frac{t_{w}}{2}$

$N_{m}=N+i d$ for interior loading

$N_{m}=N+\frac{e d}{2}$ for end loading

where $P_{p m}=$ web crippling strength; $M_{p}=$ plastic moment per unit length; $r$ and $r_{i}=$ centreline and inside corner radii, respectively; $h=$ depth of the flat portion of the web; $d=$ overall depth of the web; $t_{w}=$ thickness of the web $f_{y}=$ yield stress; $N=$ bearing length; $N_{m}=$ the assumed mechanism length; $C_{a}=$ 1.44; $C_{b}=0.0133$. The correction factors for interior loading are $i=1.3$ and 1.4 for IOF and ITF load cases, respectively, while for end loading they are $e=1.0$ and 0.6 for EOF and ETF load cases, respectively.

Table 3

AS/NZS 4600 web crippling coefficients for unfastened unlipped channels

\begin{tabular}{cccccccccc}
\hline Load case & $\mathrm{C}$ & $\mathrm{C}_{\mathrm{r}}$ & $\mathrm{C}_{\mathrm{l}}$ & $\mathrm{C}_{\mathrm{w}}$ & $\phi_{\mathrm{w}}$ & $\mathrm{r}_{\mathrm{i}} / \mathrm{t}_{\mathrm{w}}$ & $\mathrm{d}_{1} / \mathrm{t}_{\mathrm{w}}$ & $\mathrm{l}_{\mathrm{b}} / \mathrm{t}_{\mathrm{w}}$ & $\mathrm{l}_{\mathrm{b}} / \mathrm{d}_{1}$ \\
\hline EOF & 4 & 0.40 & 0.6 & 0.03 & 0.85 & $\leq 2$ & $\leq 200$ & $\leq 210$ & $\leq 2$ \\
IOF & 13 & 0.32 & 0.1 & 0.01 & 0.85 & $\leq 1$ & $\leq 200$ & $\leq 210$ & $\leq 2$ \\
\hline
\end{tabular}

$\phi_{w}=$ Capacity reduction factor

Table 4

Young and Hancock's [20] test results for EOF load case

\begin{tabular}{|c|c|c|c|c|c|c|c|c|c|c|c|}
\hline Section & $\mathrm{d}(\mathrm{mm})$ & $\mathrm{b}_{\mathrm{f}}(\mathrm{mm})$ & $\mathrm{t}_{\mathrm{w}}(\mathrm{mm})$ & $r_{i}(\mathrm{~mm})$ & $\mathrm{L}(\mathrm{mm})$ & $\mathrm{lb}(\mathrm{mm})$ & $\mathrm{f}_{\mathrm{y}}(\mathrm{MPa})$ & $\mathrm{E}(\mathrm{MPa})$ & $\mathrm{P}_{\text {Test }}(\mathrm{kN})$ & $\mathrm{P}_{\text {Test }} / \mathrm{P}_{\mathrm{AS} / \mathrm{NZS} 4600}$ & $\mathrm{P}_{\text {Test }} / \mathrm{P}_{\mathrm{Eq} \cdot(2)}$ \\
\hline $300 \times 90 \times 6$ & 298.6 & 91.0 & 6.00 & 8.4 & 1079.0 & 45.0 & 435 & 203000 & 62.5 & 0.90 & 1.11 \\
\hline $300 \times 90 \times 6$ & 298.6 & 90.9 & 6.00 & 8.4 & 1167.5 & 90.0 & 435 & 203000 & 64.8 & 0.74 & 0.94 \\
\hline $250 \times 90 \times 6$ & 249.7 & 89.9 & 5.99 & 7.9 & 925.9 & 45.0 & 445 & 203000 & 61.3 & 0.82 & 1.04 \\
\hline 250x90x6 & 249.3 & 90.1 & 5.99 & 7.9 & 1018.1 & 90.0 & 445 & 203000 & 64.3 & 0.68 & 0.86 \\
\hline $200 \times 75 \times 5$ & 198.8 & 76.0 & 4.72 & 4.2 & 764.6 & 37.5 & 415 & 203000 & 43.7 & 0.87 & 0.97 \\
\hline $200 \times 75 \times 5$ & 198.7 & 75.8 & 4.71 & 4.2 & 839.8 & 75.0 & 415 & 203000 & 49.3 & 0.78 & 0.87 \\
\hline $125 \times 65 \times 4$ & 125.6 & 65.7 & 3.84 & 3.9 & 528.8 & 32.5 & 405 & 203000 & 29.7 & 0.90 & 1.15 \\
\hline $125 \times 65 \times 4$ & 125.0 & 65.5 & 3.85 & 3.9 & 594.0 & 65.0 & 405 & 203000 & 35.3 & 0.85 & 1.01 \\
\hline $100 \times 50 \times 4$ & 99.3 & 50.5 & 3.85 & 4.1 & 440.0 & 25.0 & 440 & 203000 & 31.4 & 0.94 & 1.35 \\
\hline $100 \times 50 \times 4$ & 99.3 & 50.4 & 3.85 & 4.1 & 490.0 & 50.0 & 440 & 203000 & 34.4 & 0.83 & 1.11 \\
\hline Mean & & & & & & & & & & 0.83 & 1.04 \\
\hline $\mathrm{COV}$ & & & & & & & & & & 0.09 & 0.14 \\
\hline
\end{tabular}


Table 5

Young and Hancock's [20] test results for IOF load case

\begin{tabular}{|c|c|c|c|c|c|c|c|c|c|c|c|}
\hline Section & $\mathrm{d}(\mathrm{mm})$ & $b_{f}(m m)$ & $\mathrm{t}_{\mathrm{w}}(\mathrm{mm})$ & $r_{i}(\mathrm{~mm})$ & $\mathrm{L}(\mathrm{mm})$ & $\mathrm{l}_{\mathrm{b}}(\mathrm{mm})$ & $\mathrm{f}_{\mathrm{y}}(\mathrm{MPa})$ & $\mathrm{E}(\mathrm{MPa})$ & $\mathrm{P}_{\text {Test }}(\mathrm{kN})$ & $\mathrm{P}_{\text {Test }} / \mathrm{P}_{\text {AS/NZS4600 }}$ & $\mathrm{P}_{\mathrm{Test}} / \mathrm{P}_{\mathrm{Eq} .(2)}$ \\
\hline $300 \times 90 \times 6$ & 298.6 & 91.3 & 6.00 & 8.4 & 1125.0 & 45.0 & 435 & 203000 & 134.6 & 0.90 & 1.07 \\
\hline $300 \times 90 \times 6$ & 298.7 & 91.3 & 6.00 & 8.4 & 1169.0 & 90.0 & 435 & 203000 & 143.4 & 0.88 & 1.04 \\
\hline $250 \times 90 \times 6$ & 249.2 & 90.0 & 5.99 & 7.9 & 974.3 & 45.0 & 445 & 203000 & 132.3 & 0.84 & 1.03 \\
\hline $250 \times 90 \times 6$ & 249.8 & 89.9 & 5.99 & 7.9 & 1023.0 & 90.0 & 445 & 203000 & 142.8 & 0.83 & 0.99 \\
\hline $200 \times 75 \times 5$ & 198.7 & 75.9 & 4.72 & 4.2 & 816.8 & 37.5 & 415 & 203000 & 91.2 & 0.90 & 0.94 \\
\hline $200 \times 75 \times 5$ & 198.9 & 75.9 & 4.74 & 4.2 & 855.2 & 75.0 & 415 & 203000 & 94.5 & 0.85 & 0.86 \\
\hline $125 \times 65 \times 4$ & 125.0 & 65.5 & 3.86 & 3.9 & 587.0 & 32.5 & 405 & 203000 & 57.4 & 0.88 & 1.07 \\
\hline $125 \times 65 \times 4$ & 125.0 & 65.7 & 3.86 & 3.9 & 618.5 & 65.0 & 405 & 203000 & 63.6 & 0.90 & 1.02 \\
\hline $100 \times 50 x 4$ & 99.2 & 50.4 & 3.84 & 4.1 & 505.0 & 25.0 & 440 & 203000 & 56.3 & 0.83 & 1.18 \\
\hline $100 \times 50 \times 4$ & 99.2 & 50.4 & 3.83 & 4.1 & 529.2 & 50.0 & 440 & 203000 & 57.9 & 0.79 & 1.05 \\
\hline Mean & & & & & & & & & & 0.86 & 1.02 \\
\hline $\mathrm{COV}$ & & & & & & & & & & 0.04 & 0.08 \\
\hline
\end{tabular}

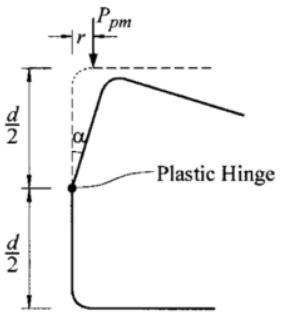

(a) One flange loading

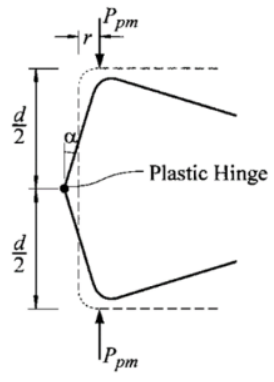

(b) Two flange loading

Fig. 6 Mechanism model proposed by Young and Hancock [20]

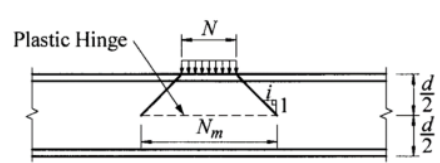

(a) Interior loading

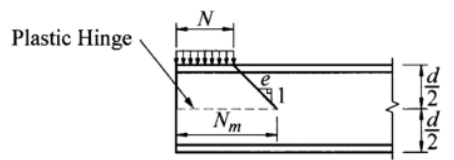

(b) End loading

Fig. 7 Plastic hinge position and mechanism length, $\left(N_{m}\right)$ assumed by [20]

\section{Experimental study}

\subsection{Test specimens}

After a detailed study of the previous studies on the web crippling behaviour of unlipped channel beams, two series of experimental studies were conducted to investigate the behaviour of cold-formed steel unlipped channels with stocky webs subject to web crippling under EOF and IOF load cases. Twenty one tests were conducted with flanges of test sections not fastened to the bearing plates. Suitable test sections and thicknesses were selected based on the available literature and the standard DuraGal sections and thicknesses commonly used in structural applications. The section depth of DuraGal steel channels varies from $75 \mathrm{~mm}$ to $300 \mathrm{~mm}$ and the thickness varies from of $4 \mathrm{~mm}$ to $8 \mathrm{~mm}$. Hence four commonly used sections with three nominal thicknesses of 4,5 and $6 \mathrm{~mm}$ were selected in the current study. Test specimen length and test setup were selected based on the AISI standard test method [29]. Tables 6 and 7 include their measured external dimensions $\left(d\right.$ and $\left.b_{f}\right)$, thicknesses $\left(t_{w}\right)$, internal radius $\left(r_{i}\right)$ and length $(L)$. Three different bearing lengths $l_{b}(50 \mathrm{~mm}$, $100 \mathrm{~mm}$ and $150 \mathrm{~mm}$ ) were used for both EOF and IOF load cases.

The nominal yield stress of DuraGal steel channel sections considered in this study is $450 \mathrm{MPa}$. However, an experimental study was undertaken to determine the accurate mechanical properties. Tensile coupon tests were conducted on four different sections to obtain their stress-strain curves and mechanical properties (elastic modulus, yield stress and ultimate strength). Test specimens were cut in the longitudinal direction of DuraGal channel sections. The base metal thickness and width of each specimen were measured at three points within the gauge length using a micrometer and a vernier calliper, respectively. The averages of these measured dimensions were used in the

calculations of mechanical properties. The tensile specimens were tested in an Instron testing machine by loading at a constant strain rate $\left(3.3 \times 10^{-4} \mathrm{~s}^{-1}\right)$ until failure. A calibrated extensometer with a $50 \mathrm{~mm}$ gauge length was used to measure the longitudinal strain. Table 8 summarizes the mechanical properties (yield stress, ultimate stress and elastic modulus) determined from the tensile coupon tests.

Table 6

Test specimen details and results for EOF load case

\begin{tabular}{ccccccccc}
\hline Test & Section & $\mathrm{d}(\mathrm{mm})$ & $\mathrm{b}_{\mathrm{f}}(\mathrm{mm})$ & $\mathrm{t}_{\mathrm{w}}(\mathrm{mm})$ & $\mathrm{r}_{\mathrm{i}}(\mathrm{mm})$ & $\mathrm{L}(\mathrm{mm})$ & $\mathrm{l}_{\mathrm{b}}(\mathrm{mm})$ & P $_{\text {Test }}(\mathrm{kN})$ \\
\hline E-1 & $230 \times 75 \times 6$ & 230.0 & 74.6 & 5.95 & 8.0 & 990 & 100 & 77.3 \\
E-2 & $230 \times 75 \times 6$ & 230.0 & 74.5 & 6.00 & 8.0 & 1140 & 150 & 89.7 \\
E-3 & $180 \times 75 \times 5$ & 179.0 & 74.9 & 4.60 & 4.0 & 840 & 100 & 56.7 \\
E-4 & $180 \times 75 \times 5$ & 179.5 & 74.9 & 4.70 & 4.0 & 991 & 150 & 65.9 \\
E-5 & $150 \times 75 \times 5$ & 149.5 & 75.1 & 4.75 & 4.0 & 750 & 100 & 61.6 \\
E-6 & $150 \times 75 \times 5$ & 151.0 & 75.0 & 4.70 & 4.0 & 900 & 150 & 63.4 \\
E-7 & $100 \times 50 \times 4$ & 100.5 & 50.0 & 3.85 & 4.0 & 450 & 50 & $38.6^{*}$ \\
E-8 & $100 \times 50 \times 4$ & 100.5 & 49.9 & 3.90 & 4.0 & 600 & 100 & $41.3^{\mathrm{T}}$ \\
E-9 & $100 \times 50 \times 4$ & 101.0 & 49.9 & 3.85 & 4.0 & 750 & 150 & $39.3^{\mathrm{T}}$ \\
\hline
\end{tabular}

* - Corresponding Young and Hancock's [20] value is $34.4 \mathrm{kN}$;

$\mathrm{T}$ - Combined twisting and web crippling failure.

Table 7

Test specimen details and results for IOF load case

\begin{tabular}{ccccccccc}
\hline Test & Section & $\mathrm{d}(\mathrm{mm})$ & $\mathrm{b}_{\mathrm{f}}(\mathrm{mm})$ & $\mathrm{t}_{\mathrm{w}}(\mathrm{mm})$ & $\mathrm{r}_{\mathrm{i}}(\mathrm{mm})$ & $\mathrm{L}(\mathrm{mm})$ & $\mathrm{l}_{\mathrm{b}}(\mathrm{mm})$ & $\mathrm{P}_{\text {Test }}(\mathrm{kN})$ \\
\hline $\mathrm{I}-1$ & $230 \times 75 \times 6$ & 229.0 & 74.9 & 6.0 & 8.0 & 840 & 50 & 136.0 \\
$\mathrm{I}-2$ & $230 \times 75 \times 6$ & 229.5 & 74.9 & 6.0 & 8.0 & 990 & 100 & 150.5 \\
$\mathrm{I}-3$ & $230 \times 75 \times 6$ & 229.5 & 74.7 & 6.0 & 8.0 & 1140 & 150 & 157.0 \\
$\mathrm{I}-4$ & $180 \times 75 \times 5$ & 180.0 & 75.7 & 4.7 & 4.0 & 690 & 50 & 88.8 \\
$\mathrm{I}-5$ & $180 \times 75 \times 5$ & 180.0 & 74.6 & 4.7 & 4.0 & 840 & 100 & 100.0 \\
$\mathrm{I}-6$ & $180 \times 75 \times 5$ & 179.0 & 75.4 & 4.7 & 4.0 & 990 & 150 & 110.7 \\
$\mathrm{I}-7$ & $150 \times 75 \times 5$ & 149.5 & 74.9 & 4.7 & 4.0 & 595 & 50 & 91.0 \\
$\mathrm{I}-8$ & $150 \times 75 \times 5$ & 150.0 & 74.9 & 4.7 & 4.0 & 750 & 100 & 103.1 \\
$\mathrm{I}-9$ & $150 \times 75 \times 5$ & 150.5 & 75.0 & 4.7 & 4.0 & 900 & 150 & 111.8 \\
$\mathrm{I}-10$ & $100 \times 50 \times 4$ & 101.0 & 49.8 & 3.8 & 4.0 & 450 & 50 & $61.9 *$ \\
$\mathrm{I}-11$ & $100 \times 50 \times 4$ & 101.0 & 50.0 & 3.8 & 4.0 & 600 & 100 & 70.5 \\
$\mathrm{I}-12$ & $100 \times 50 \times 4$ & 101.0 & 49.9 & 3.8 & 4.0 & 750 & 150 & $71.0^{\mathrm{T}}$ \\
\hline
\end{tabular}

* - Corresponding Young and Hancock's [20] value is $57.9 \mathrm{kN}$;

$\mathrm{T}$ - Combined twisting and web crippling failure. 
Table 8

Mechanical properties of test specimens

\begin{tabular}{ccccc}
\hline Section & $230 \times 75 \times 6$ & $180 \times 75 \times 5$ & $150 \times 75 \times 5$ & $100 \times 50 \times 4$ \\
\hline Yield strength (MPa) & 483 & 457 & 468 & 449 \\
Ultimate strength (MPa) & 540 & 532 & 547 & 539 \\
\hline
\end{tabular}

Elastic modulus $=200,000 \mathrm{MPa}$

\subsection{Test set-up and procedure}

Tests were conducted using a $300 \mathrm{kN}$ Instron testing machine in the Structural Laboratory. Figures 8 and 9 show the test set-up used in the web crippling tests of this research for EOF and IOF load cases, respectively (see Figures 3(a) and (b)). Two channel sections were considered for EOF and IOF load cases as recommended in [29]. A $25 \times 25 \times 5.0 \mathrm{EA}$ is fastened to the top and bottom flanges to interconnect the two sections at $1 / 4$ and $3 / 4$ points along the span. The support system was designed to ensure that the test beam had pinned supports at the top and bottom using half rounds except at one bottom support, where a roller support was simulated by ensuring a smooth surface between half round and test surfaces. Preliminary tests with and without simulating a roller support at one bottom end showed that its effect on the web crippling failure load is negligible $(<2.5 \%)$.

Test specimens were located between the bearing plates and a small load was applied first to allow the loading and support systems to settle evenly on the bearings. The measuring system was then initialised with zero values and the loading was commenced. The cross-head of the testing machine was moved at a constant rate of $0.7 \mathrm{~mm} /$ minute until failure. During the tests, the displacements of specimens were recorded in addition to the applied load. Displacement transducers were located on the test beam near the supports (for EOF load case) and near the loading point (for IOF load case) to measure the lateral (web) deflections as shown in Figures 8 and 9, respectively.

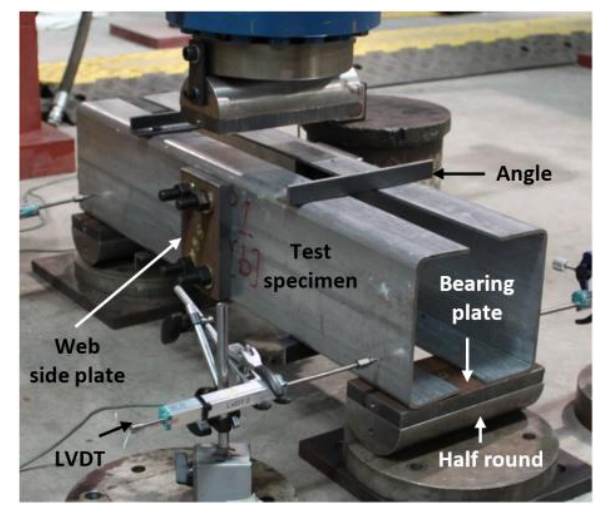

Fig. 8 Web crippling test set-up for EOF load case

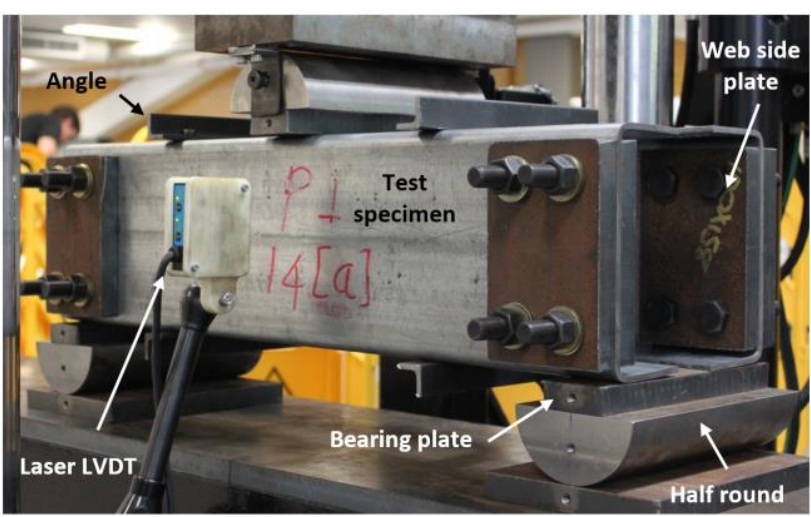

Fig. 9 Web crippling test set-up for IOF load case

\subsection{Test results and discussion}

Tables 6 and 7 show the web crippling capacities (ultimate loads) of DuraGal channel sections as obtained from this experimental study for EOF and IOF load cases, respectively while Figures 10 and 11 show the typical failure modes of channels under these load cases, respectively. Young and Hancock's [20] tests were based on a different test set-up (Figure 4) and these tests (Tables
4 and 5) were repeated in our study according to the new AISI standard test method [29] and their results reasonably agree with our corresponding results as shown in Tables 6 and 7. Their test results were found to be slightly lower compared to our results. This may be due to the varying imperfection levels and possible variations in the yield strength of the test specimens. Hence it was concluded that both these test set-ups can be used to conduct the web crippling experimental study under EOF and IOF load cases. Therefore the test results from Young and Hancock [20] are also used for further investigation together with the current test results.

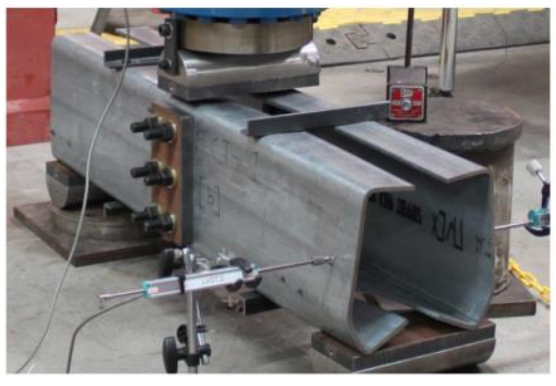

(a) Test E-1

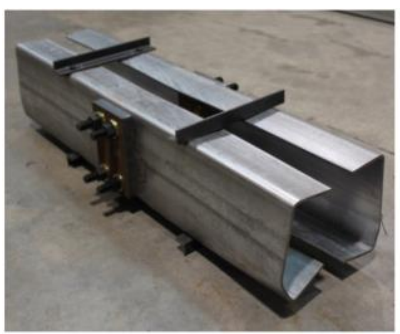

(c) Test E-3

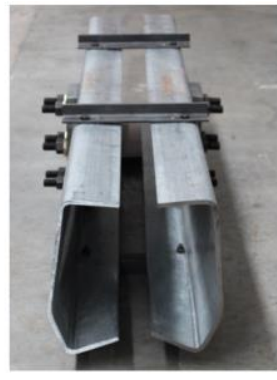

(b) Test E-2

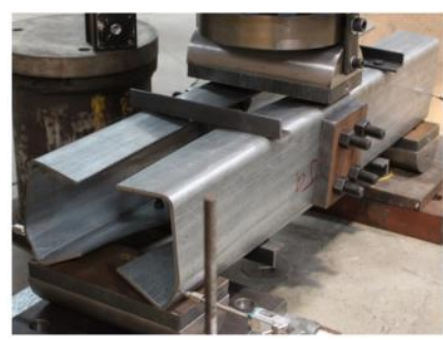

(d) Test E-5
Fig. 10 Web crippling failure modes under EOF load case

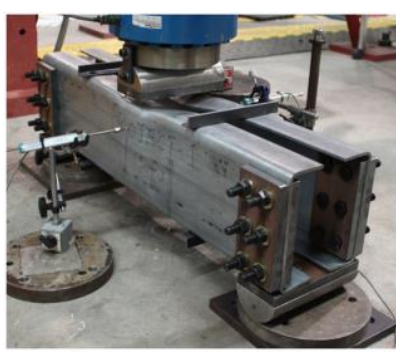

(a) Test I-2

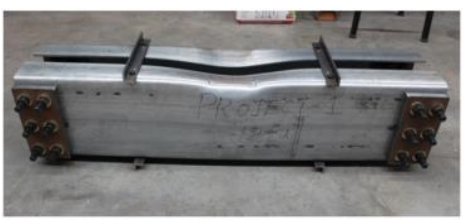

(c) Test I-2

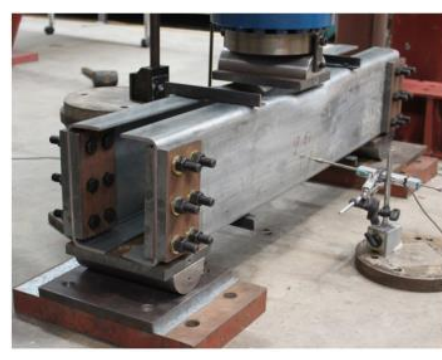

(b) Test I-3

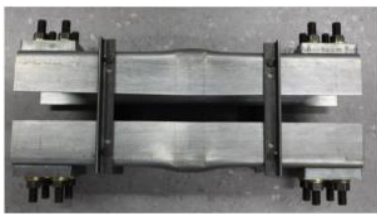

(d) Test I-7
Fig. 11 Web crippling failure modes under IOF load case

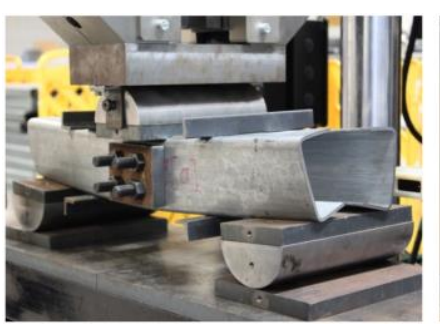

(a) Test E-8 (EOF load case)

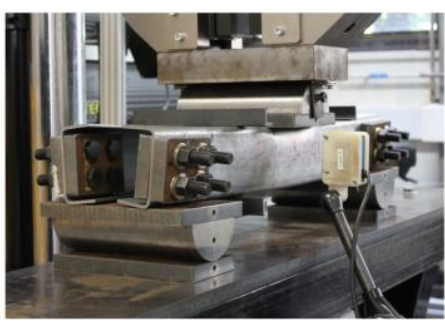

(b) Test I-12 (IOF load case)
Fig. 12 Combined twisting and web crippling failure 
Figure 12 shows the combined twisting and web crippling failure mode of channel sections when longer specimen lengths were used (Tests E8, E9 and I12). Such twisting failures were not considered here for further investigations in Tables 9 and 10. Figures 13 (a) and (b) show the typical load versus deflection curves from the web crippling tests under EOF and IOF load cases, respectively.

Tables 9 and 10 compare the experimental ultimate web crippling capacities with the predictions from the design equation (Equation 1) based on AS/NZS 4600 [3] and AISI S100 [2]. The test results from Young and Hancock [20] are also included in these tables. For the prediction of web crippling capacities, support and flange conditions were taken as unfastened, unstiffened flanges and one-flange loading or reaction based on Table 2 and the corresponding web crippling coefficients are given in Table 11. When applying the design rules of AS/NZS 4600 , the coefficients prescribed by the standards are used. For EOF load case, the mean value of test to predicted web crippling capacity of DuraGal channels by AS/NZS 4600 is 0.80 while the corresponding coefficient of variation (COV) is 0.11 . For IOF load case, the mean value of test to predicted web crippling capacity of DuraGal channels by AS/NZS 4600 is 0.83 while the corresponding COV is 0.05 . Tables 9 and 10 show that AS/NZS 4600 and AISI S100 design equations are about $34 \%$ unconservative for some cases under EOF load case, and they are about $24 \%$ unconservative under IOF load case.

Tables 9 and 10 also compare the test results with the predictions from the design equation (Eq. 2) given in Young and Hancock [20]. The coefficients proposed by Young and Hancock for use with Equation 2 are given in Table 12. For EOF load case, the mean value of test to predicted web crippling capacity of unlipped channels with stocky webs by Young and Hancock [20] is 0.96 while the corresponding coefficient of variation (COV) is 0.19. For IOF load case, the mean value of test to predicted web crippling capacity of DuraGal channels is 0.95 with a COV of 0.13 . Tables 9 and 10 show that Young and Hancock's [20] design equations are up to $35 \%$ unconservative under EOF load case and are up to $26 \%$ unconservative under IOF load case, when higher bearing lengths are used.

Based on the comparison of test results with the currently available design rules, it was found that they are not accurately predicting the web crippling capacities of stocky web channels. Hence there is a need to modify the existing design rules and/or propose new design rules to predict the web crippling capacities of unlipped channels with stocky webs.

Table 9

Comparison of test results with predictions for EOF load case

\begin{tabular}{|c|c|c|c|c|c|c|c|}
\hline \multirow[t]{2}{*}{ Test } & \multirow[t]{2}{*}{ Section } & \multirow{2}{*}{$\begin{array}{c}\mathrm{lb}_{\mathrm{b}} \\
(\mathrm{mm})\end{array}$} & \multirow{2}{*}{$\begin{array}{l}P_{\text {Test }} \\
(\mathrm{kN})\end{array}$} & \multicolumn{4}{|c|}{ Test/Predicted ultimate load ratios } \\
\hline & & & & AS/NZS & Prop. 1(a) & Eq. (2) & Prop. 2 \\
\hline E-1 & $230 \times 75 \times 6$ & 100 & 77.3 & 0.74 & 1.02 & 0.93 & 1.00 \\
\hline E-2 & $230 \times 75 \times 6$ & 150 & 89.7 & 0.73 & 1.08 & 0.86 & 1.02 \\
\hline E-3 & $180 \times 75 \times 5$ & 100 & 56.7 & 0.75 & 1.00 & 0.80 & 0.93 \\
\hline E-4 & $180 \times 75 \times 5$ & 150 & 65.9 & 0.72 & 1.03 & 0.70 & 0.90 \\
\hline E-5 & $150 \times 75 \times 5$ & 100 & 61.6 & 0.73 & 0.96 & 0.80 & 0.89 \\
\hline E-6 & $150 \times 75 \times 5$ & 150 & 63.4 & 0.66 & 0.95 & 0.65 & 0.82 \\
\hline E-7 & $100 \times 50 \times 4$ & 50 & 38.6 & 0.90 & 1.11 & 1.20 & 1.19 \\
\hline $\mathrm{E}-8^{\mathrm{Y}}$ & $300 \times 90 \times 6$ & 45 & 62.5 & 0.90 & 1.06 & 1.11 & 1.13 \\
\hline E-9 ${ }^{Y}$ & $300 \times 90 \times 6$ & 90 & 64.8 & 0.74 & 1.00 & 0.94 & 1.08 \\
\hline $\mathrm{E}-10^{\mathrm{Y}}$ & $250 \times 90 \times 6$ & 45 & 61.3 & 0.82 & 0.95 & 1.04 & 0.97 \\
\hline $\mathrm{E}-11^{\mathrm{Y}}$ & $250 \times 90 \times 6$ & 90 & 64.3 & 0.68 & 0.92 & 0.86 & 0.92 \\
\hline E-12 ${ }^{Y}$ & $200 \times 75 \times 5$ & 37.5 & 43.7 & 0.87 & 0.94 & 0.97 & 0.93 \\
\hline$E-13^{Y}$ & $200 \times 75 \times 5$ & 75 & 49.3 & 0.78 & 0.98 & 0.87 & 0.95 \\
\hline E-14 ${ }^{Y}$ & $125 \times 65 \times 4$ & 32.5 & 29.7 & 0.90 & 1.02 & 1.15 & 1.04 \\
\hline $\mathrm{E}-15^{\mathrm{Y}}$ & $125 \times 65 \times 4$ & 65 & 35.3 & 0.85 & 1.10 & 1.01 & 1.07 \\
\hline $\mathrm{E}-16^{\mathrm{Y}}$ & $100 \times 50 \times 4$ & 25 & 31.4 & 0.94 & 1.01 & 1.35 & 1.15 \\
\hline $\mathrm{E}-17^{\mathrm{Y}}$ & $100 \times 50 \times 4$ & 50 & 34.4 & 0.83 & 1.02 & 1.11 & 1.10 \\
\hline Mean & & & & 0.80 & 1.01 & 0.96 & 1.00 \\
\hline $\mathrm{COV}$ & & & & 0.11 & 0.06 & 0.19 & 0.10 \\
\hline
\end{tabular}

Y - Tests conducted by Young and Hancock [20]
Table 10

Comparison of test results with predictions for IOF load case

\begin{tabular}{|c|c|c|c|c|c|c|c|}
\hline \multirow[t]{2}{*}{ Test } & \multirow[t]{2}{*}{ Section } & \multirow{2}{*}{$\begin{array}{c}\mathrm{l}_{\mathrm{b}} \\
(\mathrm{mm})\end{array}$} & \multirow{2}{*}{$\begin{array}{l}\mathrm{P}_{\text {Test }} \\
(\mathrm{kN})\end{array}$} & \multicolumn{4}{|c|}{ Test/Predicted load ratios } \\
\hline & & & & AS/NZS & Prop. 1(a) & Eq. (2) & Prop. 2 \\
\hline $\mathrm{I}-1$ & $230 \times 75 \times 6$ & 50 & 136.0 & 0.79 & 0.93 & 1.00 & 1.00 \\
\hline $\mathrm{I}-2$ & $230 \times 75 \times 6$ & 100 & 150.5 & 0.80 & 0.94 & 0.96 & 1.03 \\
\hline $\mathrm{I}-3$ & $230 \times 75 \times 6$ & 150 & 157.0 & 0.78 & 0.92 & 0.89 & 1.00 \\
\hline $\mathrm{I}-4$ & $180 \times 75 \times 5$ & 50 & 88.8 & 0.77 & 0.96 & 0.80 & 0.83 \\
\hline $\mathrm{I}-5$ & $180 \times 75 \times 5$ & 100 & 100.0 & 0.79 & 0.98 & 0.77 & 0.85 \\
\hline $\mathrm{I}-6$ & $180 \times 75 \times 5$ & 150 & 110.7 & 0.81 & 1.01 & 0.74 & 0.87 \\
\hline $\mathrm{I}-7$ & $150 \times 75 \times 5$ & 50 & 91.0 & 0.76 & 0.95 & 0.86 & 0.87 \\
\hline $\mathrm{I}-8$ & $150 \times 75 \times 5$ & 100 & 103.1 & 0.79 & 0.98 & 0.81 & 0.88 \\
\hline $\mathrm{I}-9$ & $150 \times 75 \times 5$ & 150 & 111.8 & 0.80 & 0.99 & 0.75 & 0.87 \\
\hline $\mathrm{I}-10$ & $100 \times 50 \times 4$ & 50 & 61.9 & 0.84 & 1.03 & 1.09 & 1.12 \\
\hline $\mathrm{I}-11$ & $100 \times 50 \times 4$ & 100 & 70.5 & 0.86 & 1.05 & 0.97 & 1.10 \\
\hline $\mathrm{I}-12^{\mathrm{Y}}$ & $300 \times 90 \times 6$ & 45 & 134.6 & 0.90 & 1.05 & 1.07 & 1.15 \\
\hline $\mathrm{I}-13^{\mathrm{Y}}$ & $300 \times 90 \times 6$ & 90 & 143.4 & 0.88 & 1.03 & 1.04 & 1.15 \\
\hline $\mathrm{I}-14^{\mathrm{Y}}$ & $250 \times 90 \times 6$ & 45 & 132.3 & 0.84 & 1.00 & 1.03 & 1.05 \\
\hline $\mathrm{I}-15^{\mathrm{Y}}$ & $250 \times 90 \times 6$ & 90 & 142.8 & 0.83 & 0.99 & 0.99 & 1.06 \\
\hline $\mathrm{I}-16^{\mathrm{Y}}$ & $200 \times 75 \times 5$ & 37.5 & 91.2 & 0.90 & 1.12 & 0.94 & 0.97 \\
\hline $\mathrm{I}-17^{\mathrm{Y}}$ & $200 \times 75 \times 5$ & 75 & 94.5 & 0.85 & 1.06 & 0.86 & 0.93 \\
\hline $\mathrm{I}-18^{\mathrm{Y}}$ & $125 \times 65 \times 4$ & 32.5 & 57.4 & 0.88 & 1.08 & 1.07 & 1.06 \\
\hline $\mathrm{I}-19^{\mathrm{Y}}$ & $125 \times 65 \times 4$ & 65 & 63.6 & 0.90 & 1.10 & 1.02 & 1.08 \\
\hline $\mathrm{I}-20^{\mathrm{Y}}$ & $100 \times 50 \times 4$ & 25 & 56.3 & 0.83 & 1.02 & 1.18 & 1.13 \\
\hline $\mathrm{I}-21^{\mathrm{Y}}$ & $100 \times 50 \times 4$ & 50 & 57.9 & 0.79 & 0.97 & 1.05 & 1.08 \\
\hline Mean & & & & 0.83 & 1.01 & 0.95 & 1.00 \\
\hline $\mathrm{COV}$ & & & & 0.05 & 0.05 & 0.13 & 0.11 \\
\hline
\end{tabular}

Y - Tests conducted by Young and Hancock [20]

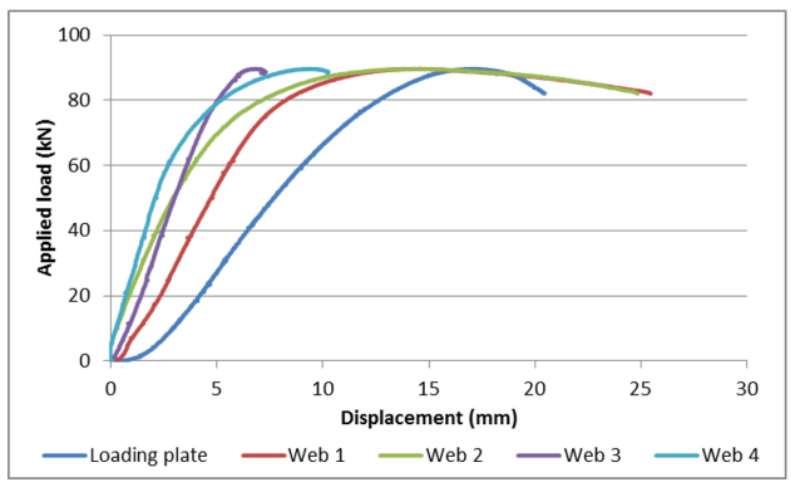

(a) EOF load case (Test E-2)

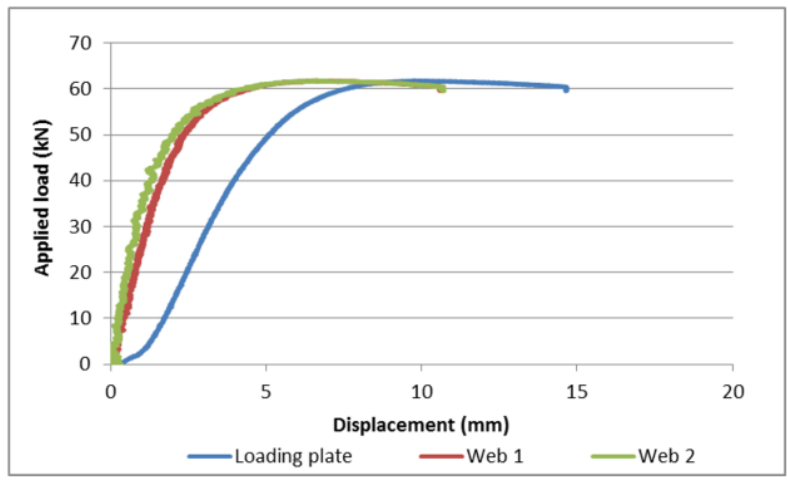

(b) IOF load case (Test I-10)

Fig. 13 Typical load versus deflection curves 


\section{Proposed design rules}

\subsection{AS/NZS 4600 and AISI S100}

Since the currently available web crippling capacity equations were found to be unconservative for unlipped channels with stocky webs, new design equations are proposed to predict the web crippling capacities of these channels based on experimental results. This approach is similar to that used in the current cold-formed steel design codes [2,3] in which Equation 1 is proposed with modified web crippling coefficients $C, C_{r}, C_{l}$ and $C_{w}$ given in Table 11. Experimental ultimate web crippling capacities are compared with the predictions from Equation 1 with the proposed coefficients (Proposal 1(a)). For EOF load case, the mean value of test to predicted web crippling capacity of DuraGal channel is 1.01 while the corresponding COV is 0.06 . For IOF load case, the mean value of test to predicted web crippling capacity of DuraGal channel is 1.01 while the corresponding COV is 0.05 . It shows that the web crippling capacities predicted by Equation 1 with proposed coefficients agree well with the experimental web crippling capacities of unlipped channels with stocky webs under IOF and EOF load cases.

The North American Cold-formed Steel Specification [2] recommends a statistical model to determine a suitable capacity reduction factor. This model accounts for the variations in material, fabrication and loading effects. The capacity reduction factor is given by Equation 6 (a).

$\varphi_{w}=1.52 M_{m} F_{m} P_{m} e^{-\beta_{0} \sqrt{\left\{V_{m}^{2}+V_{f}^{2}+C_{p} V_{p}^{2}+V_{q}^{2}\right\}}}$

with $C_{p}=\left[1+\frac{1}{n}\right]\left[\frac{m}{m-2}\right]$

where $\phi_{\mathrm{w}}=$ capacity reduction factor; $M_{m}, V_{m}=$ mean and coefficient of variation of the material factor $=1.1,0.1 ; F_{m}$ and $V_{f}=$ mean and coefficient of variation of the fabrication factor $=1.0,0.05 ; V_{q}=$ coefficient of variation of load effect $=0.21 ; \beta_{o}=$ target reliability index for cold-formed steel members $=$ 2.5; $C_{p}=$ correction factor depending on the number of tests; $P_{m}=$ mean value of the tested to predicted load ratio; $V_{p}=$ coefficient of variation of the tested to predicted load ratio, but not less than $6.5 \% ; n=$ number of tests; $m=$ degree of freedom $=n-1$.

Using Equation 6 with the mean and COV values in Table 11 gave a capacity reduction factor $\left(\phi_{\mathrm{w}}\right)$ of 0.91 for both EOF and IOF load cases for Proposal 1(a). Hence the coefficient $C$ was modified in Proposal 1(b) (Table 11) in order to propose a universal capacity reduction factor of 0.85 for web crippling subjected to EOF and IOF load cases.

\subsection{Young and Hancock [20]}

It was found that the web crippling design equations proposed by Young and Hancock [20] are unsafe for some DuraGal channels. Hence new coefficients are proposed in Table 12 to predict the web crippling capacities of DuraGal channels using Equation 2 (Proposal 2). Experimental ultimate web crippling capacities are compared with the predictions in Tables 9 and 10 using the proposed coefficients given in Table 12. For EOF load case, the mean value of test to predicted web crippling capacity of DuraGal channel is 1.00 while the corresponding $\mathrm{COV}$ is 0.10 . For IOF load case, the mean value of test to predicted web crippling capacity of DuraGal channel is 1.00 while the corresponding $\mathrm{COV}$ is 0.11 . It shows that the web crippling capacities predicted by Equation 2 with the proposed coefficients in Table 12 agree well with the experimental web crippling capacities of unlipped channels with stocky webs under IOF and EOF load cases. The corresponding capacity reduction factor $\left(\phi_{\mathrm{w}}\right)$ is 0.87 for both EOF and IOF load cases, respectively.

\section{Table 11}

Proposed coefficients based on AS/NZS 4600 design rules

\begin{tabular}{ccccccccc}
\hline Load case & Coefficients & $\mathrm{C}$ & $\mathrm{C}_{\mathrm{r}}$ & $\mathrm{C}_{\mathrm{l}}$ & $\mathrm{C}_{\mathrm{w}}$ & Mean & COV & $\phi_{\mathrm{w}}$ \\
\hline EOF & AS/NZS 4600 & 4.0 & 0.4 & 0.6 & 0.03 & 0.80 & 0.11 & 0.68 \\
EOF & Proposal 1(a) & 9.1 & 0.5 & 0.1 & 0.03 & 1.01 & 0.06 & 0.91 \\
EOF & Proposal 1(b) & 9.6 & 0.5 & 0.1 & 0.03 & 0.96 & 0.06 & 0.87 \\
IOF & AS/NZS 4600 & 13.0 & 0.32 & 0.1 & 0.01 & 0.83 & 0.05 & 0.75 \\
IOF & Proposal 1(a) & 9.0 & 0.2 & 0.1 & 0.01 & 1.01 & 0.05 & 0.91 \\
IOF & Proposal 1(b) & 9.5 & 0.2 & 0.1 & 0.01 & 0.96 & 0.05 & 0.87 \\
\hline
\end{tabular}

Table 12

Proposed coefficients based on Young and Hancock's [20] design rules

\begin{tabular}{ccccccccc}
\hline Load case & Coefficients & $\mathrm{C}_{\mathrm{a}}$ & $\mathrm{C}_{\mathrm{b}}$ & $\mathrm{e}$ & $\mathrm{i}$ & Mean & $\mathrm{COV}$ & $\phi_{\mathrm{w}}$ \\
\hline EOF & {$[20]$} & 1.44 & 0.0133 & 1 & N/A & 0.96 & 0.19 & 0.73 \\
EOF & Proposal 2 & 0.82 & 0.0110 & 3 & N/A & 1.00 & 0.10 & 0.87 \\
IOF & {$[20]$} & 1.44 & 0.0133 & $\mathrm{~N} /$ & 1.3 & 0.95 & 0.13 & 0.79 \\
IOF & Proposal 2 & 0.87 & 0.0101 & $\mathrm{~N} /$ & 2.6 & 1.00 & 0.11 & 0.87 \\
\hline
\end{tabular}

\section{Conclusions}

This paper has described an experimental study into the web crippling capacities of cold-formed steel unlipped channels with stocky webs under EOF and IOF load cases. Twenty one tests were conducted on DuraGal channel sections with stocky webs for different bearing lengths. The flanges of these channel sections were not fastened to the supports in this study. A full description of the web crippling and ultimate strength behaviour of cold-formed steel sections is presented in this paper including ultimate loads, failure modes and load-deformation curves. It was found that the test method proposed by AISI S909 [29] and the test method used by Young and Hancock [20] gave similar ultimate loads for web crippling tests under EOF and IOF load cases. A detailed comparison of current and previous test results with those predicted by the current design equations in AS/NZS 4600, AISI S100 and Young and Hancock [20] showed that these equations are unconservative for these stocky channel sections under EOF and IOF load cases. Hence new design equations were proposed within these guidelines to accurately predict the web crippling capacities of unlipped channel sections. Future research in this field should include experimental and numerical studies of all the commonly used coldformed steel beam sections with a goal to develop an improved, unified web crippling design method based on the direct strength method for inclusion in the cold-formed steel standards.

\section{Acknowledgment}

The authors would like to thank Australian Research Council and AustubeMills for their financial support (LP120200650), and the Queensland University of Technology for providing the necessary facilities and support to conduct this research project. They would also like to thank Mr. Rory McCracken and Mr Lachlan Lahey-Dillon for their assistance in performing the web crippling tests.

\section{References}

[1] Austube Mills, Available <http://www.austubemills.com.au/product/channels〉, [22 July 2014].

[2] Specifications for the Cold-formed Steel Structural Members, Cold-formed Steel Design Manual, AISI S100., American Iron and Steel Institute (AISI), Washington, USA, 2007.

[3] Cold-formed Steel Structures, AS/NZS 4600., Standards Australia (SA), Sydney, Australia, 2005.

[4] Winter G. and Pian R.H.J., Crushing Strength of Thin Steel Webs, Engineering Experiment, Bulletinno.35, Cornell University, New York, USA, 1946.

[5] Khan M. Z. and Walker A.C., "Buckling of plates subjected to localized edge loading", structural engineer, 50, 225-232, 1972.

[6] Walker A.C., Design and Analysis of Cold-formed Sections, John Wiley\& Sons, New York, 1975.

[7] Baehre R., Sheet Metal Panels for Use in Building Construction - Recent Research Projects in Sweden, Proceeding of the Third International Specialty Conference on Cold-formed Steel Structures, University of Missouri-Rolla, Rolla, Missouri, USA, 1975.

[8] Hetrakul N. and Yu W.W., Structural Behaviour of Beam Webs Subjected to Web Crippling and a Combination of Web Crippling and Bending, Final Report, Civil Engineering Study 78-4, University of Missouri-Rolla, Rolla, Missouri, USA, 1978.

[9] Wing B.A., Web Crippling and the Interaction of Bending and Web Crippling of Unreinforced Multi-web Cold-formed Steel Sections, MASc Thesis, University of Waterloo, Canada, 1981.

[10] Wing B.A. and Schuster R.M., Web crippling for Decks Subjected to Two-flange Loading, Proceedings of the Sixth International Specialty Conference on Cold-formed Steel Structures, University of Missouri-Rolla, Rolla, MO, USA, 1982.

[11] Santaputra C., Web Crippling of High Strength Cold Formed Steel Beams, Ph.D. Thesis, University of Missouri-Rolla, Rolla, Missouri, USA, 1986.

[12] Bhakta B.H., LaBoube R.A. and Yu W.W., The Effect of Flange Restraint on Web Crippling Strength, Civil Engineering Study 92-1, University of Missouri-Rolla, Rolla, Mo, USA, 1992.

[13] Prabakaran K., Web Crippling of Cold-formed Steel Sections, Project Report, Department of Civil Engineering, University of Waterloo, Waterloo, Ontario, Canada, 1993.

[14] Cain D.E., LaBoube R.A. and Yu W.W., The Effect of Flange Restraint on Web Crippling Strength of Cold Formed Steel Z-and I-sections, Final Report, Civil Engineering Study 952, University of Missouri-Rolla, Rolla, Missouri, USA, 1995.

[15] Gerges R.R., Web Crippling of Single Web Cold Formed Steel Members Subjected to End One-flange Loading, M.A.Sc. Thesis, University of Waterloo, Waterloo, Ontario, Canada, 1997. 
[16] Gerges R.R. and Schuster R.M., Web Crippling of Single Web Cold Formed Steel Members Subjected to End One-flange Loading, Fourth International Specialty Conference on Coldformed Steel Structures, St. Louis, Missouri, USA, 1998.

[17] Beshara B. and Schuster R.M., Web Crippling Data and Calibrations of Cold-formed Steel Members, Final Report, University of Waterloo, Waterloo, Canada, 2000.

[18] Rhodes J. and Nash D., "An investigation of web crushing behaviour in thin-walled beams", Thin-Walled Structures, 32, 207-230, 1998

[19] Young B. and Hancock G.J., "Web crippling behaviour of cold-formed unlipped channels", Proceedings of the 14th International Specialty Conference on Cold-formed Steel Design and Construction, Missouri, USA, 127-150, 1998.

[20] Young B. and Hancock G.J., "Design of cold-formed channels subjected to web crippling", Journal of Structural Engineering, 127, 1137-1144, 2001.

[21] Macdonald M., Heiyantuduwa M.A., Kotelko M. and Rhodes J., "Web crippling behaviour of thin-walled lipped channel beams", Thin-Walled Structures, 49, 682-690, 2011.

[22] Macdonald M. and Heiyantuduwa M.A., "A design rule for web crippling of cold-formed steel lipped channel beams based on nonlinear FEA", Thin-Walled Structures, 53, 123-130, 2012.

[23] Uzzaman A., Lim J.B.P., Nash D., Rhodes J. and Young B., "Effect of offset web holes on web crippling strength of cold-formed steel channel sections under end-two-flange loading condition", Thin-Walled Structures 65, 34-48, 2013.

[24] Uzzaman A., Lim J.B.P., Nash D., Rhodes J. and Young B., "Web crippling behaviour of cold-formed steel channel sections with offset web holes subjected to interior-two-flange loading", Thin-Walled Structures, 50, 76-86, 2012.

[25] Uzzaman A., Lim J. B. P., Nash D., Rhodes J. and Young B., "Cold-formed steel sections with web openings subjected to web crippling under two-flange loading conditions - part I: tests and finite element analysis", Thin-Walled Structures, 56, 38-48, 2012.

[26] Uzzaman A., Lim J. B. P., Nash D., Rhodes J. and Young B., "Cold-formed steel sections with web openings subjected to web crippling under two-flange loading conditions - part II: parametric study and proposed design equations", Thin-Walled Structures, 56, 79-87, 2012.

[27] Yousefi A.M., Lim J.B.P., Uzzaman A., Lian Y., Clifton G.C. and Young B., "Web crippling strength of cold-formed stainless steel lipped channel-sections with web openings subjected to interior-one-flange loading condition", Steel and Composite Structures, 21(3), 629-659, 2016.

[28] Yousefi A.M., Lim J.B.P., Uzzaman A., Lian Y., Clifton G.C. and Young, B., "Design of cold-formed stainless steel lipped channel sections with web openings subjected to web crippling under end-one-flange loading condition”, Advances in Structural Engineering, 20(7), 1024-1045, 2017.

[29] Standard Test Method for Determining the Web Crippling Strength of Cold-formed Steel Beams, TS-9-05., American Iron and Steel Institute (AISI), DC, USA, 2008.

[30] Timoshenko S.P. and Gere G.M., Theory of Elastic Stability, McGraw-Hill, New York, 1961.

[31] Walker A.C., Design and Analysis of Cold Formed Sections, John Wiley \& Sons, New York, USA, 1975

[32] Zetlin L., "Elastic Instability of Flat Plates Subjected to Partial Edge Loads", Journal of the Structural Division", ASCE Proceedings, 81, 1955.

[33] Specification for the Design of Cold-formed Steel Structural Members, American Iron and Steel Institute (AISI), Washington, D.C, U.S.A, 1996

[34] Cold-formed Steel Structures, AS/NZS 4600., Standards Association of Australia, Sydney, Australia, 1996

[35] Keerthan P. and Mahendran M., "Experimental study on web crippling strength of hollow flange channels under end-one-flange and interior-one-flange load cases", Advances in Structural Engineering, 19(6), 966-981, 2016.

[36] Steau E., Keerthan P. and Mahendran M., "Web crippling capacities of rivet fastened rectangular hollow flange channel beams under one flange load cases", Steel Construction, 9(3), 222-239, 2016.

[37] Sundararajah L., Mahendran M. and Keerthan P., "Web crippling experiments of high strength lipped channel beams under one-flange loading", Journal of Constructional Steel Research, 138, 851-866, 2017.

[38] Gunalan S. and Mahendran M., "Web crippling tests of cold-formed channel beams under two flange load cases", Journal of Constructional Steel Research, 110, 1-15, 2015 